\title{
Characterization of Polyphenolic Phytochemicals in Red Grape Pomace
}

Dimitris P Makris ${ }^{1 *}$ and Panagiotis Kefalas ${ }^{2,3}$

${ }^{1}$ School of Environment, University of the Aegean, Mitr loakim Str., Myrina-81400, Lemnos, Greece

${ }^{2}$ Food Quality and Chemistry of Natural Products, Mediterranean Agronomic Institute of China, China

${ }^{3}$ Centre International de Hautes Etudes Agronomiques Méditerranéennes, P.O. Box 85, Chania-73100, Greece

\begin{abstract}
Polyphenolic phytochemicals are of particular importance to the food, pharmaceutical and cosmetics industry, because of their unique antioxidant properties. Red grape pomace is a solid waste of the wine manufacturing process and possesses a very high polyphenolic load, hence its significance as a rich and abundant residua source. However, in many instances there is a lack of analytical data regarding its polyphenolic composition. In this study, red grape pomace originating from the Greek native cultivar Vitis vinifera var. Agiorgitiko was efficiently extracted with $57 \%$ aqueous ethanol, which is a non-toxic and environmentally benign solvent, with the aim of obtaining a polyphenol-enriched extract. The extract was subsequently analyzed by liquid chromatography-diode array-mass spectrometry analysis, in order to tentatively characterize the major phytochemicals recovered. The compounds identified were a $p$-coumaric acid derivative, three flavonol conjugates (two glucosides and a glucuronide), along with three anthocyanin pigments that occur in grape berries. Three other major phenolics detected could not be assigned to a tentative formula and their structural elucidation merits further investigation. The data generated from this study could be used in assessing the overall polyphenolic profile of the pomace from this particular Greek, native variety, which could be of value in producing commercial formulations with high antioxidant activity
\end{abstract}

Keywords: Antioxidants; Liquid chromatography-mass spectrometry; Polyphenols; Red grape pomace

Abbreviations: AAR, Antiradical Activity (mM TRE $\mathrm{g}^{-1} \mathrm{dpw}$ ); dpw: Dry Pomace Weight (g); GAE: Gallic Acid Equivalents; RGP: Red Grape Pomace; Rt: Retention Time; TRE: Trolox Equivalents; WISW: Wine Industry Solid Wastes; $\mathrm{Y}_{\mathrm{TP}}$ : Total Polyphenol Yield (mg GAE g ${ }^{-1}$ dpw)

\section{Introduction}

Solid wastes in wine industry mainly consist of solid by-products, such as pomace and stems. The waste material may account on an average $30 \%(\mathrm{w} / \mathrm{w})$ of the grapes used for wine production. Vinification wastes contain a relatively high content of polyphenolic phytochemicals $[1,2]$, which depends on the type of grape (white or red), the part of the tissue (skins, seeds etc), as well as the processing conditions (e.g. pomace contact).

Solid wastes have attracted considerable attention as potential sources of bioactive phenolic compounds, which can be used in the pharmaceutical, cosmetics and food industry. Studies regarding WISW are mainly focused on the polyphenolic composition of seeds, which are very rich in flavanols [3-5], but red grape pomace (RGP), which is composed of seeds and skins, has also been evaluated as potential source of antioxidant polyphenols [6-9]. However, although several methods of extraction have been developed for the efficient recovery of pomace polyphenols [10], there is still a significant lack of analytical data on the polyphenolic profile of RGP originating from different cultivars. The composition of RGP is defined by the polyphenols occurring in both seeds and skins, which are mainly flavanols [11,12] anthocyanins and flavonols $[13,14]$, although other minor constituents, such as stilbenes [15] and dihydroflavonols [16] have been reported. All these components are considered nutritionally important, since they may possess a variety of bioactivities [17]. Therefore, the investigation of the analytical polyphenolic composition of RGP is of undisputed significance in the development of tools and methodologies for extraction and final product formulation.

Because of the lack of analytical data regarding the polyphenolic composition, the scope of the present study was an examination on the polyphenolic composition of grape pomace from the native Greek variety Agiorgitiko (Vitis vinifera sp.). This variety is widely cultivated in the region of Peloponnese and it is the most important native species, in terms of quality wine production. The approach attempted was the examination of a polyphenol- rich pomace extract, obtained with a hydroalcoholic solution, employing liquid chromatographydiode array-mass spectrometry (LC-DAD-MS) analysis.

\section{Materials and Methods}

\section{Chemicals}

Folin-Ciocalteu reagent and gallic acid were from Fluka (Steinheim, Germany). Trolox ${ }^{\mathrm{mm}}$, gallic acid, and 2, 2-diphenyl-picrylhydrazyl (DPPH•) stable radical were from Merck (Darmstad, Germany). p-Coumaric acid was from Sigma (St. Louis, MO, U.S.A.).

\section{Vinification solid waste}

RGP was from Agiorgitiko cultivar (Vitis vinifera sp.), obtained from a winery located in Nemea (Peloponnese). The pomace was left in contact with the fermenting must for 7 days. The material was obtained immediately after pressing the pomace, transferred to the laboratory within a few hours and stored at $-40^{\circ} \mathrm{C}$ until used.

\section{Extraction procedure}

A suitable quantity of RGP (approx $4.5 \mathrm{~g}$ ) was chopped into small

*Corresponding author: Dimitris P Makris, School of Environment, University of the Aegean, Mitr. loakim Str., Myrina-81400, Lemnos, Greece, Tel: +3022540 83114; E-mail: dmakris@aegean.gr

Received October 03, 2013; Accepted October 16, 2013; Published November 20, 2013

Citation: Makris DP, Kefalas P (2013) Characterization of Polyphenolic Phytochemicals in Red Grape Pomace. Int J Waste Resources 3: 126. doi: 10.4172/2252-5211.1000126

Copyright: $\odot 2013$ Makris DP, et al. This is an open-access article distributed under the terms of the Creative Commons Attribution License, which permits unrestricted use, distribution, and reproduction in any medium, provided the original author and source are credited. 
pieces with a sharp, stainless steel cutter to facilitate extraction. The chopped material was ground with sea sand and a small portion of the extraction solvent, with a pestle and a mortar, and then left to macerate for $30 \mathrm{~min}$ in the dark. The paste formed was placed in a $100 \mathrm{~mL}$ conical flask with $25 \mathrm{~mL}$ of solvent (solvent-to-solid ratio 5.5) and extraction was performed under stirring at $700 \mathrm{rpm}$ on a magnetic stirrer for 15 min. The extract was filtered through paper filter and this procedure was repeated twice more. The extracts were then combined in a $100 \mathrm{~mL}$ volumetric flask and made to the volume. All extracts were centrifuged at $4,500 \mathrm{rpm}$ and filtered through $0.45 \mu \mathrm{m}$ syringe filters prior to analyses.

\section{Determination of total polyphenol yield $\left(\mathrm{Y}_{\mathrm{TP}}\right)$}

Analysis was carried out employing the Folin-Ciocalteu methodology [18]. In a $1.5-\mathrm{mL}$ Eppendorf tube, $0.78 \mathrm{~mL}$ of distilled water, $0.02 \mathrm{~mL}$ of sample appropriately diluted, and $0.05 \mathrm{~mL}$ of FolinCiocalteu reagent were added and vortexed. After exactly $1 \mathrm{~min}, 0.15$ $\mathrm{mL}$ of aqueous sodium carbonate $20 \%$ was added, and the mixture was vortexes and allowed to stand at room temperature in the dark, for $60 \mathrm{~min}$. The absorbance was read at $750 \mathrm{~nm}\left(\mathrm{~A}_{750}\right)$, and the total polyphenol concentration was calculated from a calibration curve, using gallic acid as a standard. Yield in total polyphenols $\left(\mathrm{Y}_{\mathrm{TP}}\right)$ was expressed as mg gallic acid equivalents (GAE) per $\mathrm{g}$ of dry weight, using the following equation:

$$
Y_{T p}\left(m g G A E g^{-1}\right)=\frac{\left(951 \times A_{750}-1.49\right) \times V}{m}
$$

Where, $\mathrm{V}$ is the volume of the extraction medium $(\mathrm{mL})$ and $m$ the dry weight of RGP (g).

\section{Measurement of the antiradical activity $\left(\mathrm{A}_{\mathrm{AR}}\right)$}

Sample $(0.025 \mathrm{~mL})$, appropriately diluted, was added to $0.975 \mathrm{~mL}$ $\mathrm{DPPH} \bullet$ solution $(100 \mu \mathrm{M}$ in methanol), and the absorbance at $515 \mathrm{~nm}$ was read at $\mathrm{t}=0\left(A_{515}{ }^{t 0}\right)$ and $\mathrm{t}=30 \mathrm{~min}\left(A_{515}{ }^{130}\right)$. Results were expressed as Trolox equivalents (mM TRE) per g of dry weight, using the following equation:

$$
A_{A R}\left(m M T R E g^{-1} d w\right)=\left(\frac{0.018 \times \% \Delta A_{515}+0.017}{m}\right) \times F_{D}
$$

As determined from linear regression, after plotting $\% \Delta \mathrm{A}_{515}$ of known solutions of Trolox against concentration; where $\% \Delta A_{515}=\frac{A_{515}^{t=0}-A_{515}^{t=30}}{A_{515}^{t=0}} \times 100, m$ the weight of dry material $(\mathrm{g})$, and $\mathrm{F}_{\mathrm{D}}$ the dilution factor.

\section{Liquid chromatography-diode array-mass spectrometry (LC- DAD-MS)}

A Finnigan MAT Spectra System P4000 pump was used coupled with a UV6000LP diode array detector and a Finnigan AQA mass spectrometer. Analyses were carried out on a Superspher RP-18, $125 \times 2 \mathrm{~mm}, 4 \mu \mathrm{m}$, column (Macherey-Nagel, Germany), protected by a guard column packed with the same material, and maintained at $40^{\circ} \mathrm{C}$. Analyses were carried out employing electrospray ionization (ESI) at the positive ion mode, with acquisition set at collision energies of 12 and $70 \mathrm{eV}$, capillary voltage $4 \mathrm{kV}$, source voltage $45 \mathrm{~V}$, detector voltage 650 $\mathrm{V}$ and probe temperature $400^{\circ} \mathrm{C}$. Eluent (A) a nd $\mathrm{MeOH}$, respectively. The flow rate was $0.33 \mathrm{~mL} \mathrm{~min}^{-1}$, and the elution programme used was as follows: $0-2 \mathrm{~min}, 0 \% \mathrm{~B} ; 2-52 \mathrm{~min}, 100 \% \mathrm{~B} ; 52-60 \mathrm{~min}, 100 \% \mathrm{~B}$.

\section{Statistical analysis}

All determinations were carried out at least in triplicate and values were averaged and given along the standard deviation (S. D.). For all statistics, SigmaPlot $^{\text {Tm }} 12.0$ and Microsoft Excel ${ }^{\text {Tw }} 2010$ were used.

\section{Results and Discussion}

\section{Effect of solvent composition}

Ethanol percentage in the solvents used varied from 28.5 to 85.5 , a range that has been previously shown to provide high yield for grape seed extraction $[3,19]$, but also grape pomace [9] and other plant material, including olive leaves (59\%) [20], black currants [21], onion peels [22] and white grape seeds, peels and stems (57\%) [23]. A hydroalcoholic solution of $57 \%$ was found to be the most effective for high polyphenol recovery, as this was manifested by estimating both $\mathrm{Y}_{\mathrm{TP}}$ and $\mathrm{A}_{\mathrm{AR}}$ (Table 1). Thus the extract obtained with 57\% ethanol was chosen for the examination of the analytical polyphenolic composition.

\section{Tentative identification of major phytochemicals}

The principal compounds detected in the extract analyzed (Figure 1) belonged to flavonol and anthocyanin classes. In particular, three flavonol and three anthocyanin conjugates were tentatively identified, along with a $p$-coumaric acid derivative (Figure 2). Three other substances could not be assigned to any known grape constituent and their identification merits further investigation.

Compound (2) (Table 2) showed an ion at $\mathrm{m} / \mathrm{z}=327$, which was assigned to its molecular ion, after considering a $\mathrm{Na}^{+}$adduct $(\mathrm{m} / \mathrm{z}=349)$ and a dehydration ion at $\mathrm{m} / \mathrm{z}=309$. The UV-vis spectrum was identical to the original $p$-coumaric acid standard. These data concurred for the identification of this compound as $p$-coumaroyl glucoside. Compound (4) displayed a molecular ion at $\mathrm{m} / \mathrm{z}=479$. Since anthocyanins are positively ionised at acidic $\mathrm{pH}$, this represents the actual molecular mass [24]. Characteristic fragment indicating the aglycone $(\mathrm{m} / \mathrm{z}=301)$ were also observed. These findings were consistent with the anthocyanin petunidin 3-O-glucoside [25]. Likewise, peak 5 gave a molecular ion at $\mathrm{m} / \mathrm{z}=493$, a diagnostic fragment of the loss of two methyl units $(\mathrm{m} /$ $\mathrm{z}=463)$, the aglycon ion $(\mathrm{m} / \mathrm{z}=315)$, and the demethylated aglycone $(\mathrm{m} / \mathrm{z}=301)$. This peak was assigned to malvidin 3-O-glucoside. Similarly, peak 10 that displayed a molecular ion at $\mathrm{m} / \mathrm{z}=639$ and the ion corresponding to the aglycone $(\mathrm{m} / \mathrm{z}=331)$, was assigned to malvidin 3-O-p-coumaroyl glucoside [26]. Compounds (6) and (7) with corresponding molecular ions at $\mathrm{m} / \mathrm{z}=479$ and 465 were found to yield the same daughter ion $(\mathrm{m} / \mathrm{z}=303)$, and corresponding $\mathrm{Na}^{+}$ adducts at $\mathrm{m} / \mathrm{z}=501$ and 487 . Compound (6) gave also a characteristic fragment at $\mathrm{m} / \mathrm{z}=561$, indicating the formation of a double adduct with $\mathrm{CH}_{3} \mathrm{COOH}$ and $\mathrm{Na}^{+}$. These compounds were identified as quercetin 3-O-glucuronide and quercetin 3-O-glucoside, respectively [27]. In a similar fashion, compound (8) displayed a molecular ion at $\mathrm{m} /$ $\mathrm{z}=479$ and adducts with both $\mathrm{Na}^{+}$and $\mathrm{CH}_{3} \mathrm{COOH}$ at $\mathrm{m} / \mathrm{z}=561$. Ions at $\mathrm{m} / \mathrm{z}=509$ and 501 were also assigned to adducts with $\mathrm{MeOH}$ and $\mathrm{Na}^{+}$, respectively. The $\mathrm{m} / \mathrm{z}=317$ also yielded a $\mathrm{MeOH}$ adduct at $\mathrm{m} /$ $\mathrm{z}=347$. Based on these data, this compound was tentatively identified as isorhamnetin 3-O-glucoside.

\section{Conclusions}

Red grape pomace is an industrial by-product with a wide

\begin{tabular}{|c|c|c|}
\hline Solvent (\% v/v EtOH) & $\mathbf{Y}_{\text {TP }}{\left.\text { (mg GAE } \mathbf{~ g}^{-1} \mathbf{~ d p w}\right)}$ & $\mathbf{A}_{\text {AR }}\left(\mathbf{m M ~ T R E ~}^{-1} \mathbf{~ d p w}\right)$ \\
\hline 28.5 & $25.46 \pm 2.40$ & $2.15 \pm 0.09$ \\
\hline 57.0 & $72.59 \pm 2.21$ & $2.67 \pm 0.10$ \\
\hline 85.5 & $48.17 \pm 4.07$ & $1.89 \pm 0.04$ \\
\hline
\end{tabular}

Table 1: Values determined for $Y_{T P}$ and $A_{A R}$ of the extracts obtained using aqueous solvents with varying amounts of EtOH. 


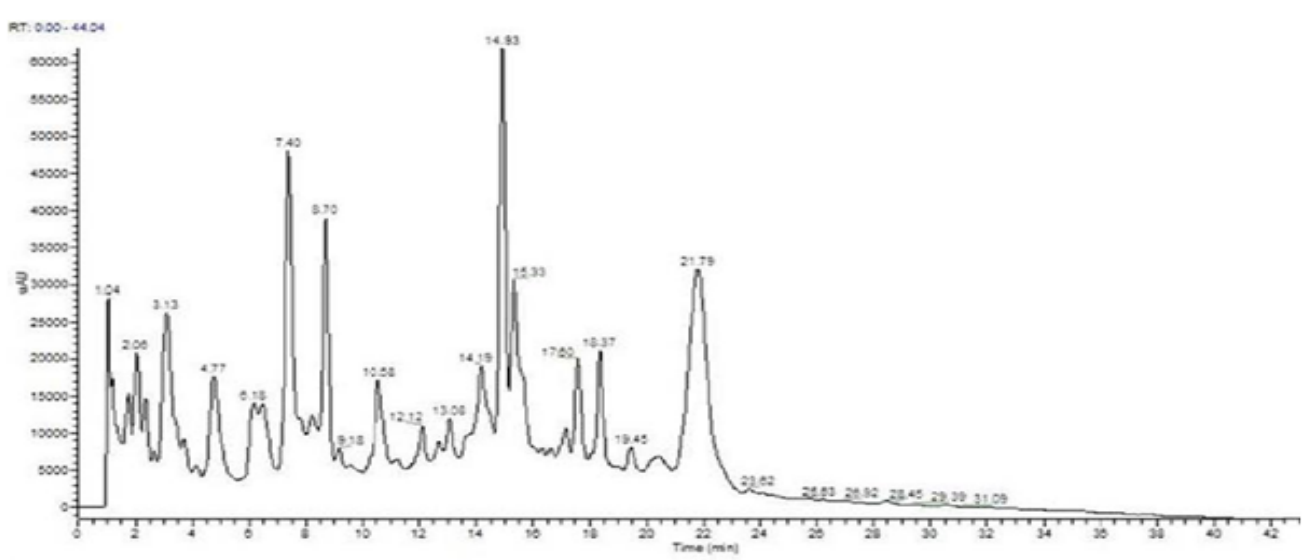

Figure 1: Chromatogram of the RGP extract monitored at $320 \mathrm{~nm}$. Peak assignment according to retention time (Rt) is given in Table 2.

\begin{tabular}{|c|c|c|c|c|c|c|}
\hline Peak No. & Rt (min) & $\lambda \max$ & {$[\mathrm{M}]^{+}(\mathrm{m} / \mathrm{z})$} & {$[\mathrm{M}+\mathrm{H}]^{+}(\mathrm{m} / \mathrm{z})$} & Fragment ions $(\mathrm{m} / \mathrm{z})$ & Tentative identity \\
\hline 1 & 3.13 & $280,296,328(s)$ & & - & $385,329,203$ & Unknown \\
\hline 2 & 7.40 & 310 & & 327 & 349,309 & p-Coumaroyl glycoside \\
\hline 3 & 8.70 & 277 & & 675 & $409,349,327,259,231$ & Unknown \\
\hline 4 & 13.08 & $250,342(s), 522$ & 479 & & 301 & Petunidin 3-O-glucoside \\
\hline 5 & 14.19 & 250,524 & 493 & & $463,331,315,301$ & Malvidin 3-O-glucoside \\
\hline 6 & 14.93 & 254,354 & & 479 & $561\left[\mathrm{CH}_{3} \mathrm{COOH}+\mathrm{Na}\right]^{+}, 501[\mathrm{Na}]^{+}, 303$ & Quercetin glucuronide \\
\hline 7 & 15.33 & 252,356 & & 465 & $487[\mathrm{Na}]^{+}, 303$ & Quercetin glucoside \\
\hline \multirow[t]{2}{*}{8} & 17.60 & 252,354 & & 479 & $531[\mathrm{MeOH}+\mathrm{Na}]^{+}, 509[479+\mathrm{MeOH}]^{+}$ & Isorhamnetin glucoside \\
\hline & & & & & $501[\mathrm{Na}]^{+}, 347[317+\mathrm{MeOH}]^{+}, 317$ & \\
\hline 9 & 18.37 & 272 & & 695 & $517,387,355,195,181,163$ & Unknown \\
\hline 10 & 21.79 & 254,534 & 639 & & 331 & Malvidin 3-O- $p$-coumaroyl glucoside \\
\hline
\end{tabular}

Table 2: Spectral characteristics and tentative identification of the major polyphenols detected in the RGP extract analysed.

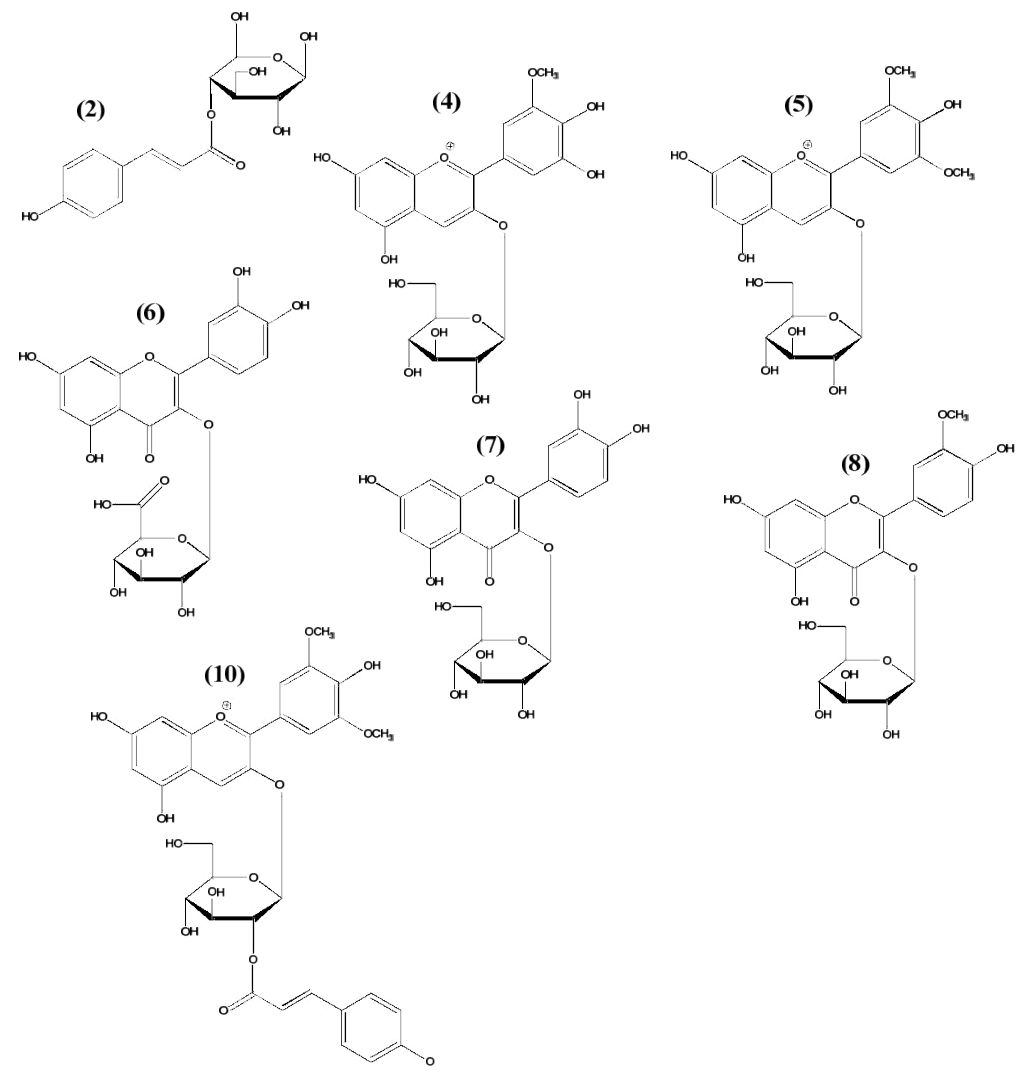

Figure 2: Chemical formulae of the major polyphenolic components tentatively identified in the RGP extract. Assignments are given in Table 2. 
Citation: Makris DP, Kefalas P (2013) Characterization of Polyphenolic Phytochemicals in Red Grape Pomace. Int J Waste Resources 3: 126. doi: 10.4172/2252-5211.1000126

diversification, which depends on several factors, such as genetic (varietal) potential, treatment, post-disposal handling etc. Therefore, the examination of such waste materials from various sources might reveal the occurrence of a spectrum of substances. In the study presented herein, red grape pomace originating from the Greek native cultivar V. vinifera var. Agiorgitiko was efficiently extracted with $57 \%$ aqueous ethanol, to retrieve polyphenolic compounds. Ten principal polyphenols were detected and seven of them were tentatively identified on the basis of UV-vis and mass spectral data. The analyses revealed that the substances detected were a phenylpropanoid, derivative of $p$-coumaric acid, as well as anthocyanin pigments and flavonol glycoconjugates. Further research is needed to better illuminate the complex composition of this particular food industry by-product.

\section{References}

1. González-Paramás AM, Esteban-Ruano S, Santos-Buelga C, de PascualTeresa S, Rivas-Gonzalo JC (2004) Flavanol content and antioxidant activity in winery byproducts. Journal of Agricultural and Food Chemistry 52: 234-238.

2. Makris DP, Boskou G, Andrikopoulos NK (2007a) Polyphenolic content and in vitro antioxidant characteristics of wine industry and other agri-food solid waste extracts. Journal of Food Composition and Analysis 20: 125-132.

3. Yilmaz Y, Toledo RT (2006) Oxygen radical absorbance capacities of grape/ wine industry byproducts and effect of solvent type on extraction of grape seed polyphenols. Journal of Food Composition and Analysis 19: 41-48.

4. Guendez R, Kallithraka S, Makris DP, Kefalas P (2005) An analytical survey of the polyphenols of seeds of varieties of grape (Vitis vinifera $\mathrm{sp}$.) cultivated in Greece: implications for exploitation as a source of value-added phytochemicals. Phytochemical Analysis 16: 17-23.

5. Karvela E, Makris DP, Kalogeropoulos N, Karathanos VT, Kefalas P (2009) Factorial design optimization of grape (Vitis vinifera) seed polyphenol extraction. European Food Research and Technology 229: 731-743.

6. Louli V, Ragoussis N, Magoulas K (2004) Recovery of phenolic antioxidants from wine industry by-products. Bioresoure Technology 92: 201-208.

7. Kammerer D, Claus A, Schieber A, Carle A (2005) A novel process for the recovery of polyphenols from grape (Vitis vinifera L.) pomace. Journal of Food Science 70: C157-C163.

8. Pinelo M, Rubilar M, Jerez M, Sineiro J, Núñez JM (2005) Effect of solvent temperature, and solvent-to-solid ratio on the total phenolic content and antiradical activity of extracts from different components of grape pomace. Journal of Agricultural and Food Chemistry 53: 2111-2117.

9. Makris DP, Boskou G, Chiou A, Andrikopoulos NK (2008a) An investigation on factors affecting recovery of antioxidant phenolics and anthocyanins from red grape (Vitis vinifera) pomace employing water/ethanol-based solutions. American Journal of Food Technology 3: 164-173.

10. Fontana AR, Antoniolli A, Bottini R (2013) Grape pomace as a sustainable source of bioactive compounds: extraction, characterization, and biotechnological applications of phenolics. Journal of Agricultural and Food Chemistry 61: 89879003.

11. Mildner-Szkudlarz S, Zawirska-Wojtasiak R, Gośliński M (2010) Phenolic compounds from winemaking waste and its antioxidant activity towards oxidation of rapeseed oil. International Journal of Food Science and Technology 45: $2272-2280$

12. Rubilar M, Pinelo M, Shene C, Sineiro J, Nuñez MJ (2007) Separation and HPLC-MS identification of phenolic antioxidants from agricultural residues: almond hulls and grape pomace. Journal of Agricultural and Food Chemistry 55: 10101-10109.

13. Kammerer D, Claus A, Carle R, Schieber A (2004) Polyphenol screening of pomace from red and white grape varieties (Vitis vinifera L.) by HPLC-DAD-MS/ MS. Journal of Agricultural and Food Chemistry, 52: 4360-4367.

14. Amico V, Chillemi R, Mangiafico S, Spataflora C, Tringali C (2008) Polyphenol enriched fractions from Sicilian grape pomace: HPLC-DAD analysis and antioxidant activity. Bioresource Technology 99: 5960-5966.

15. Anastasiadi M, Pratsinis H, Kletsas D, Skaltsounis AL, Haroutounian SA (2010) Bioactive non-coloured polyphenols content of grapes, wines and vinification by-products: evaluation of the antioxidant activities of their extracts. Food Research International 43: 805-813.

16. Jin ZM, Bi HQ, Liang NN, Duan CQ (2010) An extraction method for obtaining the maximum non-anthocyanin phenolics from grape berry skins. Analytical Letters 43: 776-785.

17. Pezzuto JM (2008) Grapes and human health: a perspective. Journal of Agricultural and Food Chemistry 58: 6777-6784.

18. Arnous A, Makris DP, Kefalas P (2002) Correlation of pigment and flavanol content with antioxidant properties in selected aged regional wines from Greece. Journal of Food Composition and Analysis 15: 655-665.

19. Shi J, Yu J, Pohorly J, Young JC, Bryan M, Wu Y (2003) Optimization of the extraction of polyphenols from grape seed meal by aqueous ethanol solution. Journal of Food, Agriculture and Environment 1: 42-47.

20. Japón-Luján R, Luque-Rodríguez JM, Luque de Castro MD (2006) Dynamic ultrasound-assisted extraction of oleuropein and related biophenols from olive leaves. Journal of Chromatography A 1108: 76-82.

21. Cacace JE, Mazza G (2003) Optimization of extraction of anthocyanins from black currants with aqueous ethanol. Journal of Food Science 68: 240-248.

22. Kiassos E, Mylonaki S, Makris DP, Kefalas P (2009) Implementation of response surface methodology to optimise extraction of onion (Allium cepa) solid waste phenolics. Innovative Food Science and Emerging Technologies 10: 246-252.

23. Makris DP, Boskou G, Andrikopoulos NK (2007b) Recovery of antioxidant phenolics from white vinification solid by-products employing water/ethanol mixtures. Bioresource Technology 98: 2963-2967.

24. Kefalas P, Makris DP (2006) Liquid chromatography-mass spectrometry techniques in flavonoid analysis: recent advances. In Antioxidant Plant Phenols: Sources, Structure- Activity Relationship, Current Trends in Analysis and Characterization. Research Signpost, Kerala, India.

25. Monrad JK, Howard LR, King JW, Srinivas K, Mauromoustakos A (2010) Subcritical solvent extraction of anthocyanins from dried red grape pomace. Journal of Agricultural and Food Chemistry 58: 2862-2868.

26. Sidani B, Makris DP (2011) Interactions of natural antioxidants with red grape pomace anthocyanins in a liquid model matrix: stability and copigmentation effects. Chemical Industry \& Chemical Engineering Quarterly 17: 59-66.

27. Makris DP, Boskou G, Andrikopoulos NK, Kefalas P (2008b) Characterisation of certain major polyphenolic antioxidants in grape (Vitis vinifera cv. Roditis) stems by liquid chromatography-mass spectrometry. Food Research and Technology 226: 1075- 1079 . 